\title{
El paisaje en la distribución de los túmulos funerarios del valle de Azapa, durante el periodo formativo, norte de Chile ${ }^{1}$
}

\author{
Iván Muñoz ${ }^{2}$ y Francisca Zalaquett ${ }^{3}$
}

\begin{abstract}
RESUMEN
Los antecedentes de las prospecciones del valle de Azapa (coordenadas UTM (datum WGS84) $795.600 \mathrm{~N}$ y 19.362.000 E; 795.0000 N y 19.378.000 E), ubicado en el norte de Chile, reconocen un patrón de asentamiento durante el periodo Formativo representado por conjuntos de túmulos que se distribuyen a lo largo del valle, construidos sobre terrazas y faldeos de cerros cercanos a los lugares de vertientes y humedales. Este estudio se basa en una prospección extensiva e intensiva con el propósito de determinar la ubicación de los túmulos, definir su distancia con los recursos de agua, medir el grado de ocupación del área de los complejos de túmulos y determinar el grado de visualización entre los distintos sectores de túmulos. La discusión de estos objetivos ha entregado una interesante información que se analizará bajo propuestas de la arqueología del paisaje.
\end{abstract}

Palabras clave: Túmulos, patrón de asentamiento, arqueología paisaje

\begin{abstract}
The survey records of the Azapa Valley (UTM coordinates (datum WGS84) $795.600 \mathrm{~N}$ y 19.362.000 E; 795.000 y N 19.378.000 E), located in the North of Chile, present a settlement pattern of burial mound complexes distributed along the valley's terraces and hill skirts near runoffs and wetlands during the Formative period. Because of this, we suggest that an ideological organization of incipient farmers existed, which was related with the burial rituals and the offering deposits made in the mound construction in the desert landscape. The burial mounds were visible from different sectors of the valley, built in huaca trails up to the Indigenous-Hispanic contact period. This research is based on an extensive and intensive prospection, with the purpose of determining the burial mounds location, defining the distance between the mounds and water resources, measuring the occupation history of the mound complex area, and determining the visibility degree between the different mound sectors. The discussion of these objectives has provided interesting information, which we will be analyzed with the new Landscape Archaeology theories.
\end{abstract}

Key words: Mounds, settlement pattern, landscape archaeology.

Estudio ejecutado bajo los auspicios del proyecto Fondecyt 1085106. Artículo recibido el 2 de agosto de 2010, aceptado el 5 de septiembre de 2011 y corregido el 29 de septiembre de 2011.
2 Departamento de Antropología, Universidad de Tarapacá (Chile). E-mail: imunoz@uta.cl

3 Centro de Estudios Mayas, Universidad Nacional Autónoma de México (México).

E-mail: panchaahau@hotmail.com 
Los túmulos funerarios de la fase Alto Ramírez (500 a. C. al 200 d. C.) son el primer indicio de arquitectura prehistórica monumental que se remonta a 2.500 años en los valles costeros del norte de Chile (Focacci y Erices, 1971; Rivera, 1976; Muñoz, 1980; Núñez, 1989). Constituyen, después de Chinchorro, las principales evidencias para entender el proceso de complejidad social incipiente, y los cambios operados en los grupos pescadores y recolectores de la costa del extremo norte de Chile. Están construidos por capas de tierra y fibra vegetal; los de mayor altura alcanzan los diez metros, los cuales además de ser funerarios, fueron objeto de ceremonias hasta la llegada del europeo.

Muñoz (2009), al discutir las estrategias de organización de estas tempranas poblaciones agrícolas, señala que la construcción de estos túmulos es resultado de un proceso local, siendo las poblaciones pescadoras-recolectoras que poblaron el territorio costero del extremo norte de Chile desde los 7.000 años a. C. los actores sociales representativos. El registro arqueológico muestra cómo estas transformaciones aparecen vinculadas al aumento demográfico y a cambios en la movilidad, que derivaron en el establecimiento de un régimen de vida sedentario, en la planificación de sus asentamientos, en la organización y jerarquización de los espacios domésticos-funerarios. En dicho contexto, los túmulos funerarios constituyen las muestras visibles de un patrón de asentamiento de agricultores incipientes que comenzaron a demarcar territorios, posiblemente en función de la disponibilidad de los recursos del medio, demandando una legitimidad sobre dichos espacios aduciendo posiblemente un uso ancestral, lo cual se visibilizó a través de la construcción de estos montículos.

Basados en esta propuesta, el presente artículo analiza aspectos en torno a: ¿cómo estuvieron organizados territorialmente los túmulos en el contexto del patrón de asentamiento de las poblaciones Alto Ramírez?, ¿cuáles eran las relaciones entre estos túmulos?, ¿todos tenían una función similar, o se pueden observar variantes?, y en este contexto, ¿qué rol cumplieron estos montículos como estructuras monumentales en la relación con los recursos naturales, en el caso específico las vertientes de agua, quebradas y cerros circundantes?

\section{Los túmulos como monumentos del paisaje construido}

El estudio que se propone se centra dentro de los planteamientos teóricos de la arqueología del paisaje, el que tiene como elemento fundamental la dimensión social (Clarke, 1977) que se caracteriza por una construcción dinámica enraizada con la cultura (Criado, 1993). Gianotti (2005) señala dos interesantes hipótesis generales que se desprenden de la arqueología del paisaje y que se analizarán en el presente trabajo: (a) las actividades espaciales están siempre organizadas de un modo coherente con la representación del mundo que la cultura produce, y (b) todos los ámbitos espaciales (asentamientos, cementerios, lugares de producción, hitos geográficos, entre otros) están presentes en el paisaje.

De lo anteriormente planteado, se puede señalar que los túmulos fueron los monumentos más representativos de los agricultores iniciales de los valles costeros de Arica; en los alrededores de estos, construyeron sus viviendas y pequeños campos de cultivos. Por su construcción elevada y volumen es posible que estas construcciones hayan sido elementos estructuradores del paisaje social. Por otro lado, la presencia de ofrendas y entierros hizo que estos túmulos representaran la materialización de la vida, de la muerte y del sentido que la sociedad le dio a sus antepasados y a su paisaje (Knapp \& Ashmore, 1999; López Mazz, 2001). En este contexto, en estos lugares se establecieron relaciones sociales extendidas por medio de la participación de actividades rituales que conforman una identidad común, lo cual les otorgaba una historia social que los legitimaba. Estos espacios son dinámicos, ya que las personas crean y son limitadas por estructuras que marcan su vida, donde experimentan y actúan dentro de su sociedad.

Un ejemplo etnográfico que ayuda a entender el significado y funcionalidad de las estructuras monticulares se encuentra en el trabajo de Dillehay (1991) sobre la sociedad mapuche, donde señala que la construcción 
de estos montículos legitima derechos territoriales de autoridades locales en un contexto social dinamizado por relaciones de parentesco con grupos externos. Además, constituyen una memoria basada en el surgimiento de la relación espacio-temporal entre antepasados con el mundo de los vivos y la tierra.

A nivel arqueológico esta propuesta cobra gran importancia, ya que permite visualizar la sociedad escribiendo su identidad en el paisaje, a través de las acciones de sus miembros. Al mismo tiempo, el uso de los espacios recrea la memoria, las experiencias pasadas, expectativas, deseos y la comunicación con los otros.

Los monumentos como los túmulos tienen, por lo menos, tres rasgos comunes: son identificatorios, relacionales e históricos (Augé, 2000). Cuando se habla de lugares construidos, hay que especificar que muchos de estos lugares poseen características que los destacan, ya que se consagran a los cultos, asambleas políticas y religiosas, lo que permite crear las condiciones de una memoria que se vincula con ciertos lugares y contribuye a reforzar su carácter sagrado.

Una parte fundamental de la caracterización de los monumentos es la complejidad de los ritos y símbolos que están en juego; visto de esta manera, el ritual de la construcción de los túmulos debió ser una actividad compleja. Por lo tanto, como lo señala Bradley (1998), se hizo necesaria la participación de un grupo humano organizado. En el caso de los túmulos de Azapa, estos se ubican en lugares de confluencias entre quebradas, situación que permitió la formación de humedales y vertientes. Se piensa que la apropiación de estos escenarios naturales fue utilizada como estrategia para la configuración de sus territorios sociales.

\section{Construcción de los monumentos funerarios y patrón de entierro}

Los antecedentes arqueológicos reconocen que los túmulos se construyeron en espacios ya explorados por las tempranas poblaciones formativas vinculadas con la fase Faldas del Morro y/o Azapa, debido a eviden- cias de entierros ubicados en el nivel bajo de los cementerios AZ-14 y AZ-71, agricultores que habrían comenzado con las primeras prácticas agrícolas en el valle de Azapa (Santoro, 1980a; Muñoz, 1989). Desde el punto de vista constructivo estos monumentos se caracterizan por una estructura artificial de forma monticular de sección plano convexa, formadas por capas alternadas de sedimentos, cantos rodados y capas de fibra vegetal. La presencia de restos de carbón, huesos, pequeños maderos, e incluso fragmentos de huesos humanos hallados en las capas de sedimentos de los túmulos, sugieren la hipótesis que en su construcción se ocuparon materiales de asentamientos más tempranos provenientes de cementerios o viviendas, posiblemente en desuso. En cuanto a los entierros, estos se caracterizan por ser primarios y secundarios, estos últimos removidos en distintos grados, algunos sin cráneos, extremidades o presentando solamente el cráneo como entierro. Como consecuencia de este complejo patrón de entierro, la construcción de los túmulos al parecer se hizo en varias etapas; así lo testifican los antecedentes cronológicos que varían en un mismo túmulo AZ-70 (Muñoz, 1987).

\section{Metodología y análisis de elementos del paisaje dentro de su patrón de asentamiento}

El objetivo principal de este trabajo fue delimitar el espacio ocupado por la arquitectura monumental de túmulos en el valle de Azapa. Posteriormente reconstruir a través de la información planimétrica la distribución espacial de los distintos asentamientos con su correspondiente caracterización del entorno geográfico y, por último, analizar por medio de la arqueología del paisaje posibles relaciones entre los túmulos funerarios y los recursos naturales.

Como metodología de campo, se efectuó un recorrido de superficie en el sector medio y bajo del valle, el cual estuvo estructurado en tres etapas:

Prospección indirecta. Basada en el análisis de la fotografía aérea, cartografía del servicio Geográfico Militar y la Información Geográfica Satelital. Se recurrió a la información 
registrada en Google Earth y otros sistemas de Información Geográfica.

Prospección intensiva. Con el objeto de contrastar y completar la información obtenida a través de la prospección indirecta se realizaron mapas arqueológicos detallados y se georreferenciaron los yacimientos. A cada punto se le tomó su posición absoluta dentro del conjunto de túmulos y se dibujó el contorno para obtener así la forma y diámetro de cada túmulo. Se consideraron, además, las actuales superficies aradas que contenían evidencias. Se integró información complementaria a los túmulos, tales como cementerios en fosas bajo superficies, así como pisos o estructuras habitacionales vinculadas con el periodo Formativo.

1) Prospección intensiva dirigida. Esta se hizo en lugares donde no se obtuvo información satelital; por lo tanto se recorrieron las laderas de los valles antes mencionados.

2) Para estas actividades se confeccionó una base de datos que incluía antecedentes relacionados con la ubicación con coordenadas UTM de los yacimientos, la descripción general del entorno (relieve, vegetación, relación con elementos naturales, visibilidad, accesos, propiedad de la tierra), una descripción arqueológica general del yacimiento (dimensiones, límites, estructuras visibles, hallazgos de materiales, cronología relativa, vinculación con otros yacimientos, estado patrimonial). Además, se registró en cada montículo en particular, información relacionada a dimensiones, altura, diámetro, formas, materiales en superficie, entre otros. Se confeccionaron planos específicos con la distribución y caracterización de sus componentes culturales (cementerios, asentamientos, entre otros).

3) Con la información procesada en el software Sistema de Información Geográfica ArcGis 9.2 se insertó la base de datos y se obtuvieron las relaciones de distancia hacia los recursos hidrológicos, la densidad de cada asentamiento de túmulos, y con el análisis de cuencas visibles se obtuvo la visibilidad desde cada asentamiento calculado con una altura de una persona de $1,60 \mathrm{~m}$, los que fueron corroborados posteriormente en campo. Además, este sistema permitió confeccionar un inventario del patrimonio monumental del valle, donde se registraron las características que tienen que ver directamente con la integridad de las entidades arqueológicas concretas, en este caso los túmulos, y de los principales agentes causantes de su alteración. Se elaboró una clave general que ayudó a clasificar el estado de conservación en tres niveles (si se encuentra saqueado, intervenido por caminos agrícolas, si es una propiedad privada o está en condiciones de conservación).

\section{Análisis de los datos}

Se presentarán, por medio de una serie de mapas, los datos procesados que arrojó la prospección, donde se encuentra la ubicación de los túmulos, su relación y distancia con los recursos hídricos, el área de ocupación y rangos de visibilidad.

En la Figura $\mathrm{N}^{0} 1$ se puede determinar una clara concentración de túmulos en la ladera sur del valle; se distribuyen en nodos construidos en terrazas fluviales y faldeos de cerros, ocupando espacios en forma de anfiteatros, protegidos por grandes cerros. Dichos lugares presentan trazados de senderos que comunican los sectores de Las Riberas, San Lorenzo, Las Maitas, Pampa Alto Ramírez y Cerro Sombrero. En todos estos sectores existen varios complejos de túmulos, los que se relacionan espacialmente con las vertientes denominadas El Gallito, Media Luna y Mita Chica. En la ladera norte, los sectores donde se construyeron los complejos de túmulos corresponden a Cerro Moreno, San Miguel de Azapa y Las Ánimas; en estos tres sectores las condiciones de hábitat son las más adecuadas para los asentamientos humanos, es decir, espacios abiertos, estratégicos, relacionados con recursos de agua y tierras agrícolas.

En la costa se ubican dos complejos de túmulos, Mo3, descritos por Bird (1943) y El Laucho o PI. Millar 7 descrito por Focacci (1974); ambos complejos de túmulos se relacionan a poblaciones del periodo Formativo dentro de un rango de tiempo de alrededor de 500 años. El patrón de entierro se caracteriza por cuerpos en posición decúbito dorsal con las piernas flexionadas, envueltos en mantas tejidas con hilados de lana de gruesa. 
Figura $N^{\circ} 1$

Ubicación de sitios con túmulos y de sitios residenciales en el valle de Azapa durante el periodo Formativo

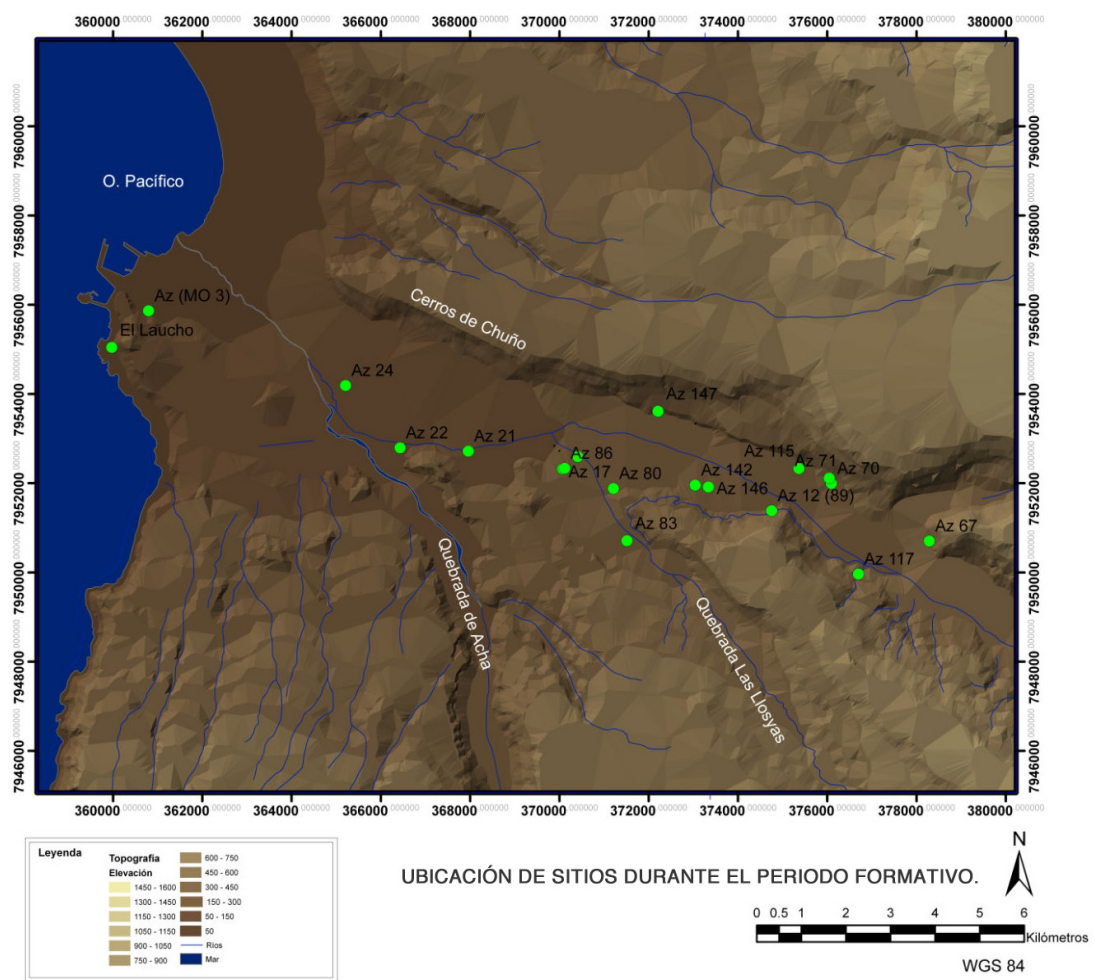

Fuente: Instituto Geográfico Militar, Zona A, escala 1:50.000. UTM WGS 84.

Las ofrendas están constituidas por tecnología de pesca como anzuelos, extractores de mariscos, arpones, además de tiestos cerámicos confeccionados con pastas gruesas, antiplástico de arena y fibras vegetales de baja cocción. Se registran además cestos con formas de plato, en cuyo interior se hallaron restos de porotos (Phaseolus vulgaris), calabazas (Cucurbita sp.) y yuca (Manihot utilissima). A diferencia de los túmulos de Azapa, Morro 3 como Pl. Millar 7 presentan capas de fibra vegetal de menos espesor; las dimensiones de estas cubren solamente el cuerpo del difunto y no una extensión mayor. En su gran mayoría estos montículos funerarios están compuestos por tierra y restos de desperdicios marinos (conchas).

La Figura $N^{\circ} 2$ grafica el diámetro promedio de 1,3 km de distancia entre los túmulos funerarios y las vertientes, lo que habría permitido un acceso a los recursos de agua y vegetales a muy corta distancia. Esto habría permitido desplazamientos diarios tanto para la búsqueda del recurso hídrico para el consumo humano, como para recolectar plantas y camarones y cazar roedores, evidencias que han sido halladas en los registros de túmulos como Az-70, Az-122 y Az-67. Otros desplazamientos fueron para proteger y cuidar las plantaciones de porotos (Phaseolus vulgaris), ají (Capsicum annuum), calabazas (Cucurbita sp.), y yuca (Manihot utilissima), entre otros cultivos, que las poblaciones tenían alrededor de las vertientes. Existe una excepción con el sitio Az 142, que está ubicado estratégicamente entre los accesos al valle desde la quebrada de Las Llosyas y la del Diablo, más lejano de las vertientes y de los túmulos. Este sitio corresponde a un túmulo que fue ex- 
cavado por Espoueys (1973), describe el hallazgo de tres cuerpos de adultos en posición decúbito dorsal con piernas flexionadas. Los cuerpos están envueltos en mantas gruesas y tejidos de algodón decorados con listas; un cuerpo presenta estera de tejido fino, restos de mazorcas de maíz (Zea mays), paja y un canasto tipo capacho.

Figura $\mathrm{N}^{\circ} 2$

Ubicación de túmulos y vertientes

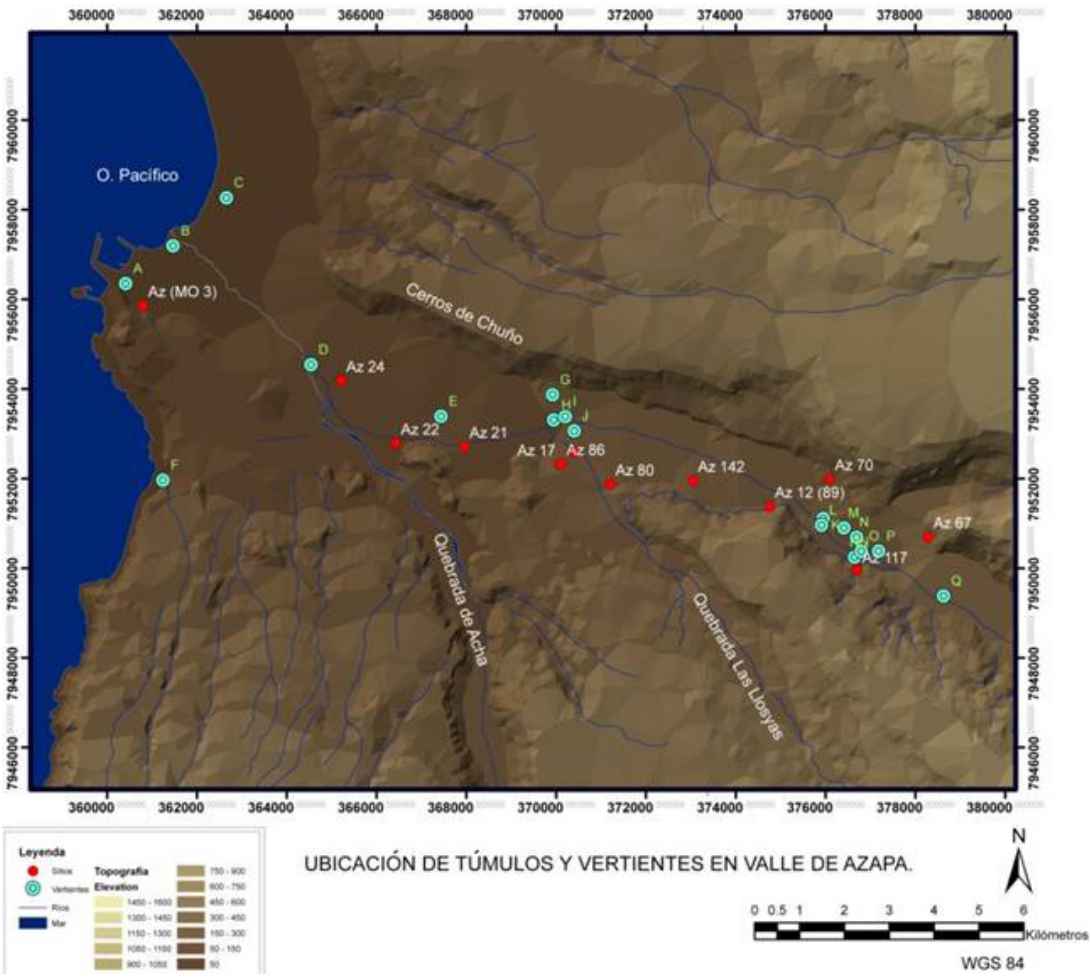

Fuente: Instituto Geográfico Militar, Zona A, escala 1:50.000. UTM WGS 84.

En la Figura $\mathrm{N}^{\circ} 3 \mathrm{a}$ ) podemos observar que el sitio Mo3 está ubicado en los faldeos del morro de Arica, dicho morro se caracteriza por un abrupto peñón $150 \mathrm{~m}$ de altura; por su imponente estructura granítica constituye un punto de referencia tanto de los asentamientos prehispánicos ubicados en la costa como los del interior del valle de Azapa. Espacialmente pudo haber constituido un punto de referencia que conectaba los pescadores arraigados en la costa, como Pl. Miller 7 con los grupos del valle como las poblaciones de túmulos que se encontraban desarrollando la agricultura temprana.
La Figura $\mathrm{N}^{\circ} 3 \mathrm{~b}$ ) ilustra el yacimiento $\mathrm{Az}$ 24, emplazado junto al humedal cerro San Miguel. En este túmulo, Espoueys (1973) describe el hallazgo de dos cuerpos ubicados en las capas de sedimentos, cubiertos de fibra de sorona (Tessaria absinthioides), junquillos (Juncos $s p$ ) y totora (Typha angustifolia). Estaban los cuerpos en posición decúbito dorsal, con las piernas flexionadas cubiertos con estera. Recientes excavaciones ejecutadas por el equipo de trabajo registró en el túmulo 1 de Az-24 el hallazgo de dos bolsas con forma de talega, halladas en las capas inferiores del túmulo a manera de ofrendas. 
Figura $\mathrm{N}^{\circ} 3$

Relación de túmulos con vertientes y humedales

a)

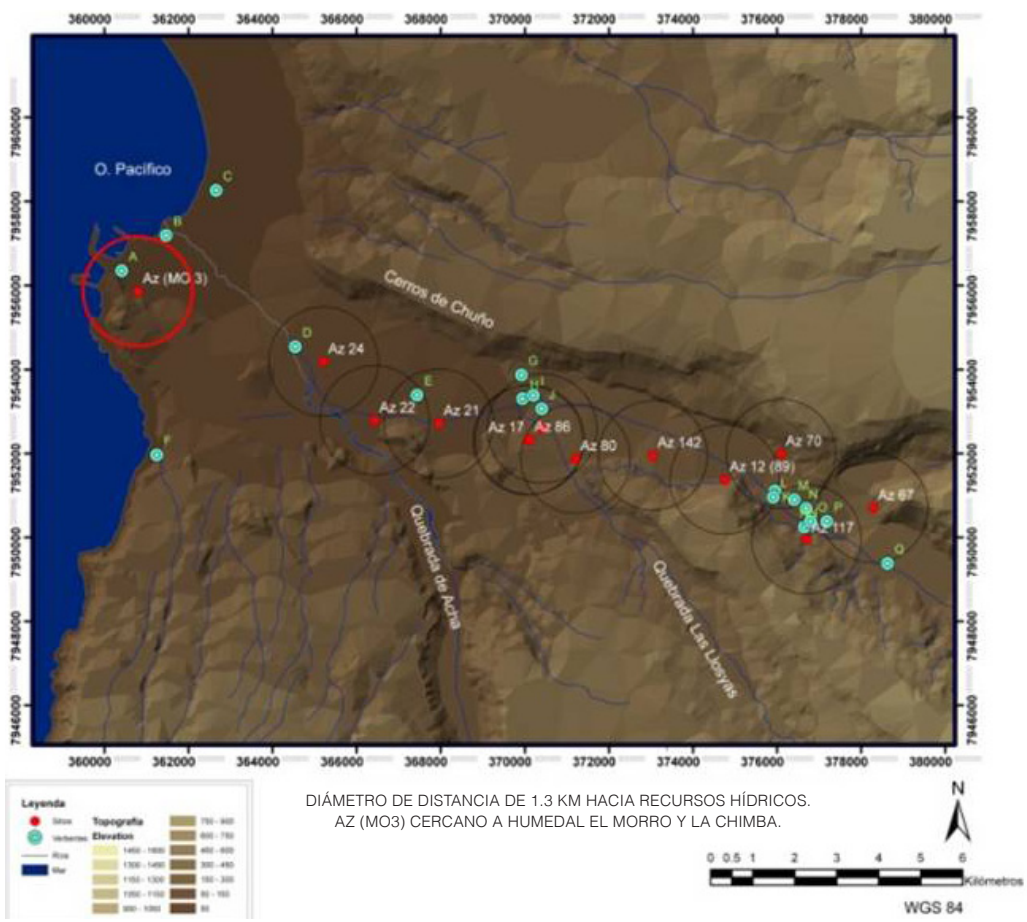

b)

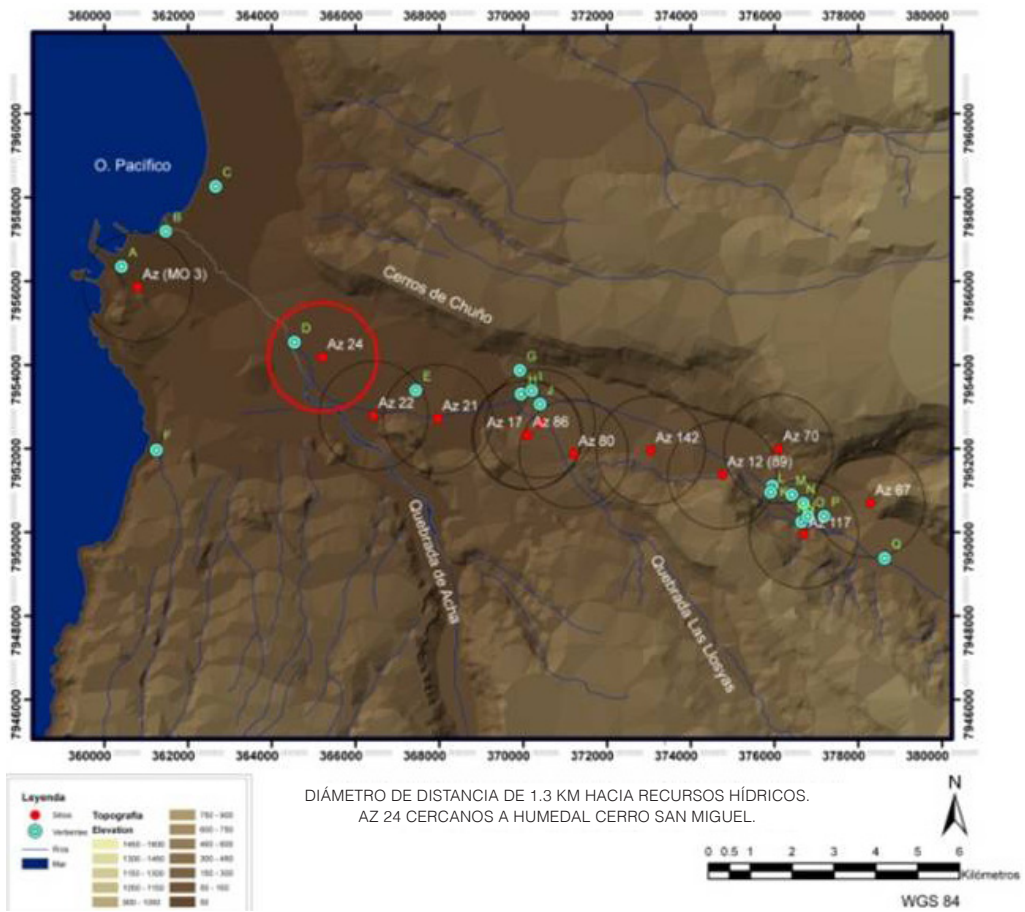

Fuente: Instituto Geográfico Militar, Zona A, escala 1:50.000. UTM WGS 84. 
Figura $N^{\circ} 4$

Distancia promedio entre túmulos y vertientes

a)

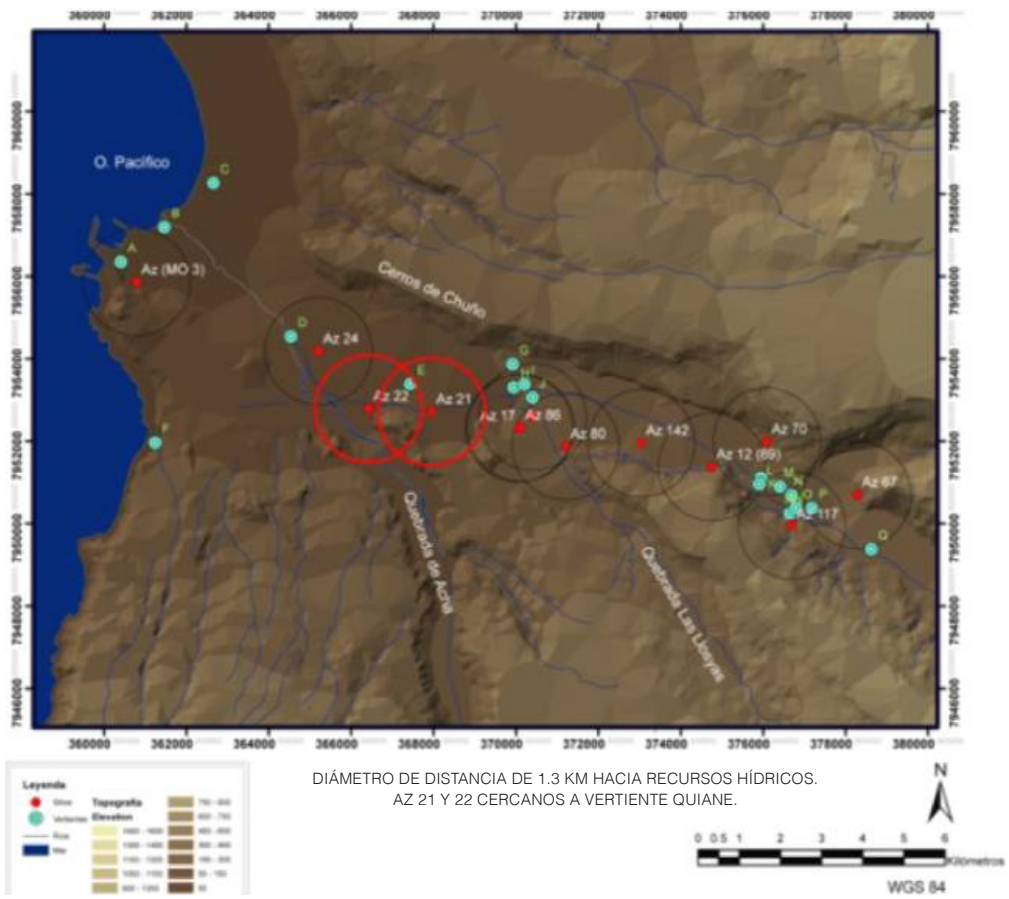

b)

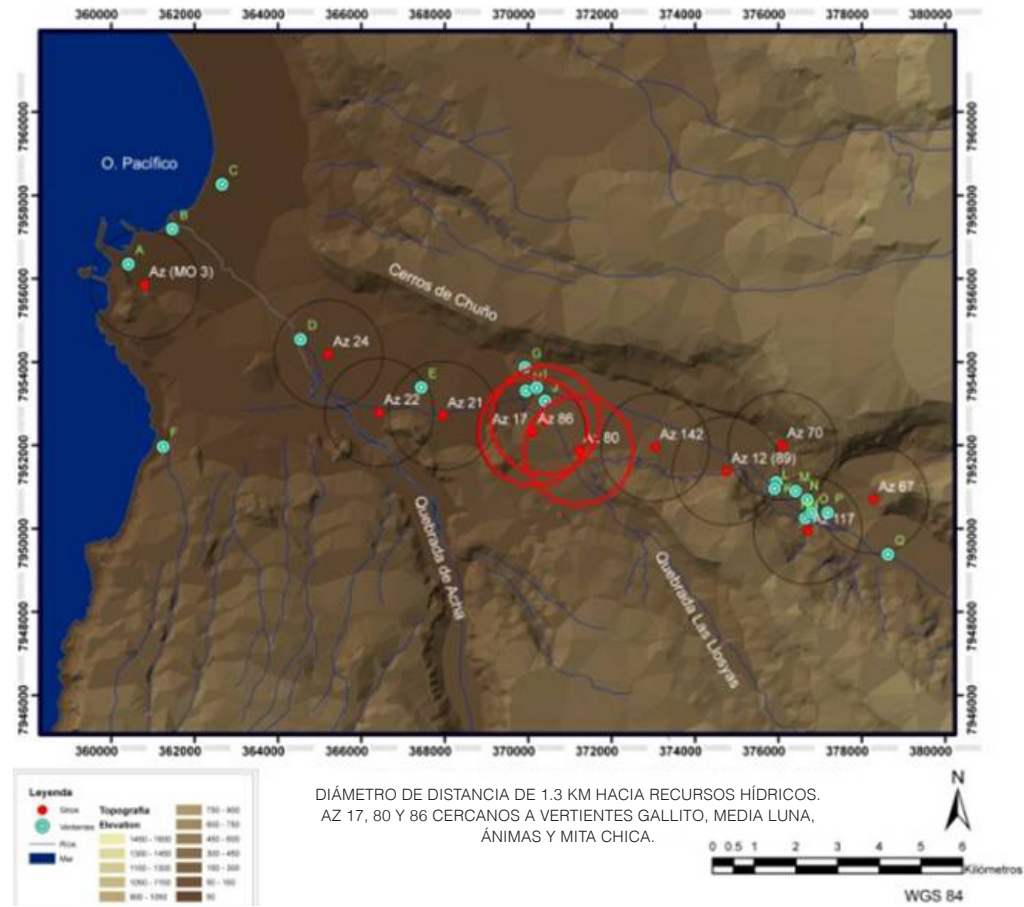

Fuente: Instituto Geográfico Militar, Zona A, escala 1:50.000. UTM WGS 84. 
El acceso de las personas al valle de Azapa se realizaba por la quebrada de Acha, donde se encontraban los asentamientos: Az 21 y 22, ubicados al oriente y occidente del sector de cerro Sombrero, acentuando de manera estratégica el acceso principal al valle (Figura $\mathrm{N}^{\circ} 4 \mathrm{a}$ ). Paralelamente a estas estructuras monumentales, se encuentran los paneles de geoglifos denominados La TropiIla, los que refuerzan la importancia de este espacio en la configuración del paisaje ritual de la zona. El sitio Az 21 tiene 4 túmulos, y fue registrado por Espoueys (1973), quien describió los cuerpos de un niño y dos adultos en posición decúbito dorsal con piernas flexionadas, cubiertos con mantas gruesas de lanas de colores oscuros sin teñir y fragmentos de cestería, ofrendas de ceramios fragmentados y una cuchara. El túmulo Az 22, registrado por Dauelsberg (1995) y Espoueys (1973), está, también, relacionado al periodo Formativo. En su interior se registraron dos entierros perturbados, sentados, con las piernas flexionadas; los cuerpos están cubiertos por una gruesa manta tejida de lana sin decoración. Este túmulo espacialmente se halla cercano a 1,5 km del humedal de cerro San Miguel, a dos km de la ocupación más temprana del valle denominada Acha 2 (Muñoz, 1993).

En cuanto a la explotación de los recursos hídricos se piensa que, tanto para las poblaciones de Az-24 como Az-21 y Az-22, el acceso más directo pudo haber sido el humedal del cerro San Miguel, con opciones más lejanas como el humedal de La Chimba y la desembocadura del río San José y la vertiente de la quebrada de Quiani, en la costa sur de Arica.

La Figura $N^{\circ} 4 b$ ) ilustra el mayor conjunto de túmulos, ubicados en la pampa de Alto Ramírez; corresponde a los túmulos Az-17, Az-86. En el conjunto monumental Az-17 existen en la actualidad 7 túmulos, uno de grandes dimensiones, que alcanza los 10 metros de altura, denominado El Abuelo. Posiblemente en este sector hubo más túmulos, que fueron destruidos por la ampliación agrícola. Junto a ellos, se halla el conjunto de túmulos de Az-80 constituido por 23 túmulos ubicados justo en el acceso a la quebrada de Las Llosyas. Los tres asentamientos se relacionan espacialmente con las vertientes
El Gallito, Media Luna, Mita Chica y Las Ánimas; constituyen en la actualidad el sector de mayor número de túmulos (35 en total). Sin embargo, en la década de los setenta este mismo sector alcanzó a tener unos 100 túmulos aproximadamente. Independientemente de no saber la cantidad exacta de túmulos construidos, el sector de Alto Ramírez constituyó el área de asentamientos con mayor evidencias; esto debió haber sido como consecuencia de su cercanía a las mayores vertientes, la que en su conjunto formaron un gran humedal en el sector circundante a la pampa de Alto Ramírez que incluyó Las Maitas y Cerro Sombrero.

En la Figura $\mathrm{N}^{0} 5$ se observan varios nodos de túmulos; el primero corresponde a Az-12, conformado por tres túmulos; estos se hallan a $150 \mathrm{~m}$ al suroeste del pukara San Lorenzo. Desde ahí se observa la costa de Arica, así como el sector de San Miguel, donde está el complejo de túmulos Az-70. Este conjunto tiene 16 túmulos, constituyéndose en el mayor nodo de túmulos ubicados en la ladera norte. En Az-70 se han realizado las mayores excavaciones, ocho en total, proporcionando por lo tanto una gran información biocultural relacionada a cementerios de túmulos. Dichos estudios corresponden a Focacci y Erices (1972/1973), Rivera et al. (1974), Rivera (1976), Muñoz (1980; 1987; 1989; 1995/1996) y Romero et al. (2004). Otro conjunto de túmulos ubicados entre la confluencia del valle de Azapa y la quebrada del Diablo es Az-67, corresponde a seis túmulos ubicados en un área extendida. Esta zona fue la más poblada con este tipo de construcciones tumulares, las que con el tiempo han sido arrasadas en la actualidad por los cultivos de olivos. Los túmulos de Az-12 están relacionados a las vertientes El Gallito y la Media Luna; los túmulos de Az-70 y Az-67 se relacionan estrechamente a las vertientes El Pejerrey, Matavaca, La Noria, San Miguel, El Socavón, La Concepción y Caniviri ubicados entre la quebrada del Diablo por el noreste y las Ánimas por el noroeste.

La Figura $N^{0} 6$ ilustra la cantidad de túmulos por sitio y el área en metros cuadrados de cada sitio. Se proponen rangos de sitios según su densidad de ocupación; los de primer orden tienen de 1 a 4 túmulos 
y un área de ocupación de $100 \mathrm{~m}^{2}$ a 2.400 $\mathrm{m}^{2}$ aproximadamente, ya que se encuentran más concentrados; en este caso tendríamos a $\mathrm{Az}$ (Mo3) con 1 túmulo y $100 \mathrm{~m}^{2}, \mathrm{Az}-22$ con 1 túmulo y $214 \mathrm{~m}^{2}, \mathrm{Az}-24$ con 1 túmulo y $1.000 \mathrm{~m}^{2}$, Az-12 (89) con 3 túmulos y $1.311 \mathrm{~m}^{2}$, hasta Az-21 con 4 túmulos y $2.404 \mathrm{~m}^{2}$, todos con un patrón concentrado. Los del segundo, poseen un rango de 4 a 7 con un área mayor, ya que manifiestan un patrón más disperso, el que pudo deberse a la destrucción de los túmulos o por una mayor extensión territorial; en este grupo encontramos a Az-117 con 4 túmulos en un área de $6.177 \mathrm{~m}^{2}, \mathrm{Az}-17$ con 7 túmulos en un área de $24.388 \mathrm{~m}^{2}$ y Az-67 con 4 túmulos en un área de $19.399 \mathrm{~m}^{2}$. El tercer rango está formado por entre 16 y 23 estructuras tumulares con un patrón más concentrado y un mayor número de túmulos, como es el caso de Az-70 con 16 túmulos en un área de $81.672 \mathrm{~m}^{2}$ y Az-80 con 23 túmulos en un área de $15.476 \mathrm{~m}^{2}$. Los sitios con una mayor área ocupada por túmulos funerarios se ubican en la confluencia de la quebrada de Las Llosyas con el valle (Az-17, 80 y 86), donde se tiene una concentración de vertientes y en la confluencia de la quebrada del Diablo con el valle (Az-67, 70 y 117).

Se decidió incorporar en el análisis de paisaje los aspectos de visibilidad, que serán resultados de la acción social, donde los seres humanos determinan consciente e inconscientemente qué rasgos serán visibles o invisibles (Criado, 1993). Para este caso, se tendrían esencialmente dos; la primera es la estrategia de exhibición, donde existe una voluntad consciente de exhibir procesos o resultados de la acción social (expresado en la visibilidad espacial), junto a una estrategia monumental, que se proyecta temporal-

Figura $\mathrm{N}^{0} 5$

Nodos de túmulos asociados a vertientes

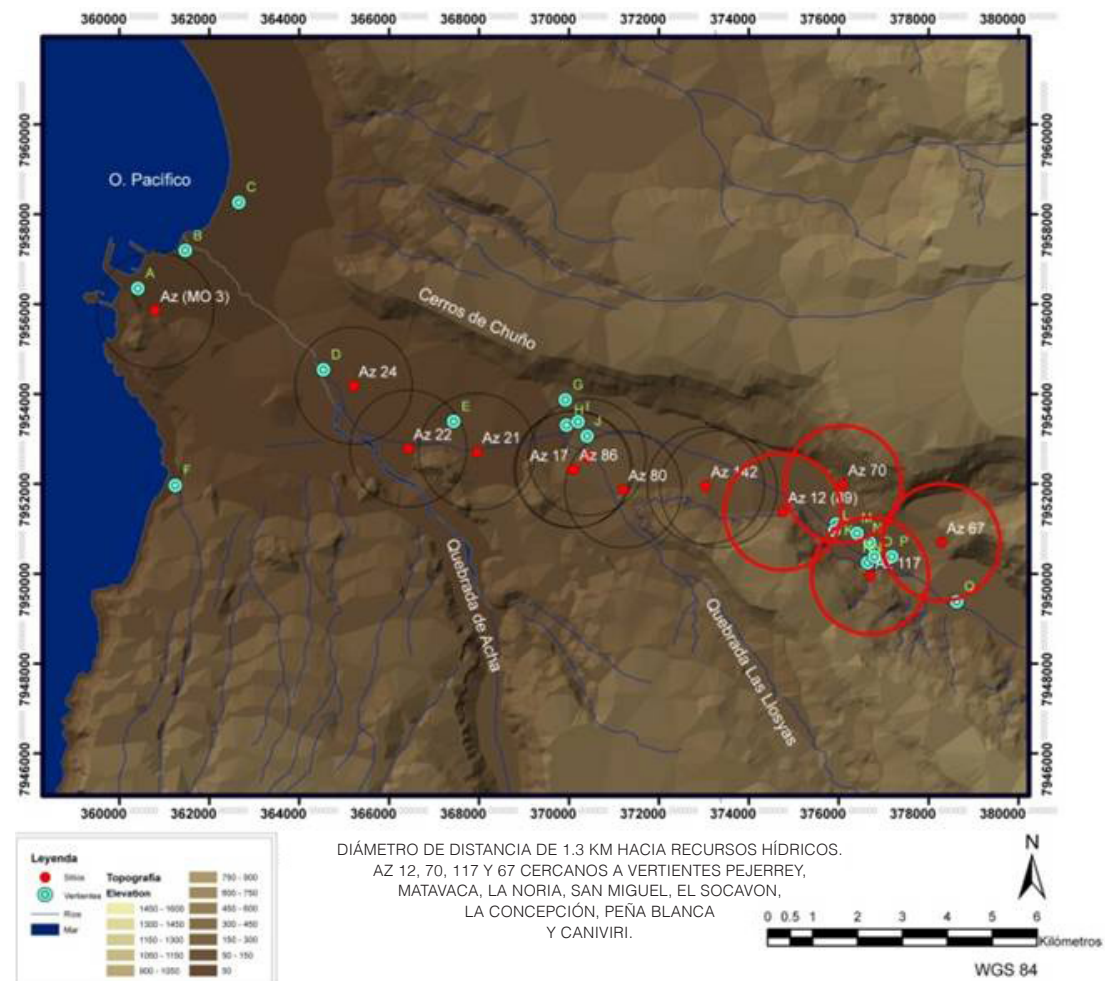

Fuente: Instituto Geográfico Militar, Zona A, escala 1:50.000. UTM WGS 84. 
Figura $\mathrm{N}^{\circ} 6$

Cantidad de túmulos y áreas de ocupación

a)

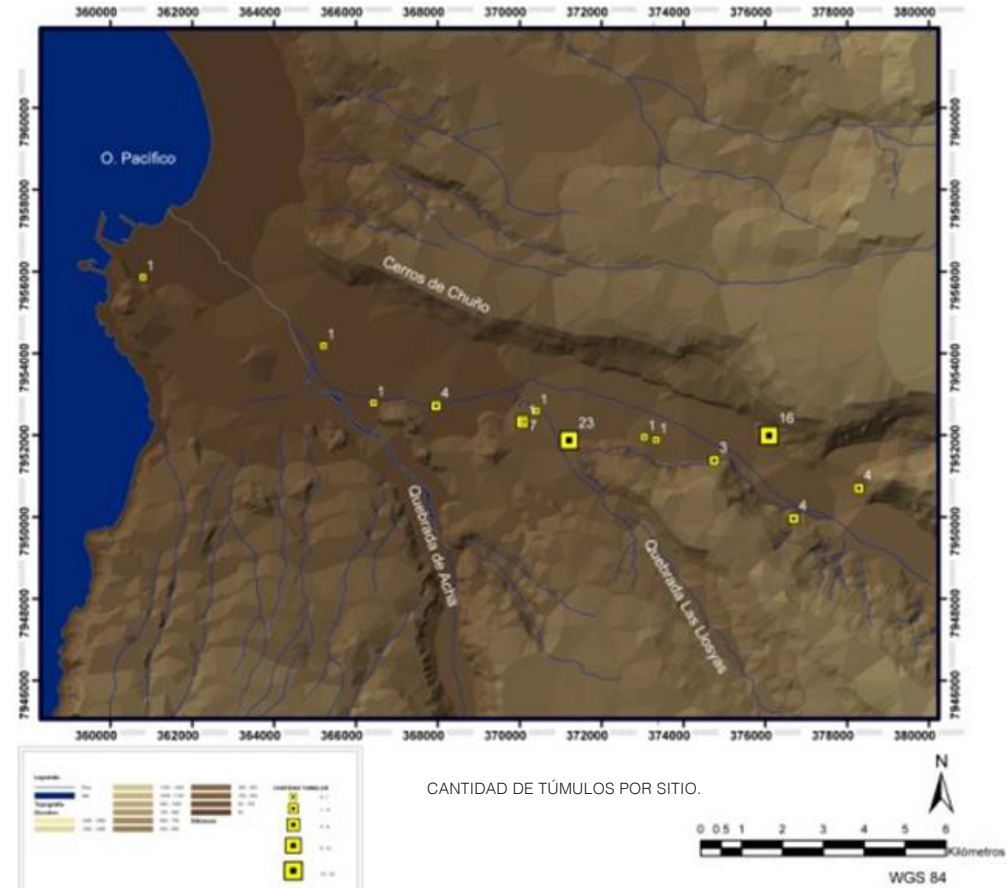

b)

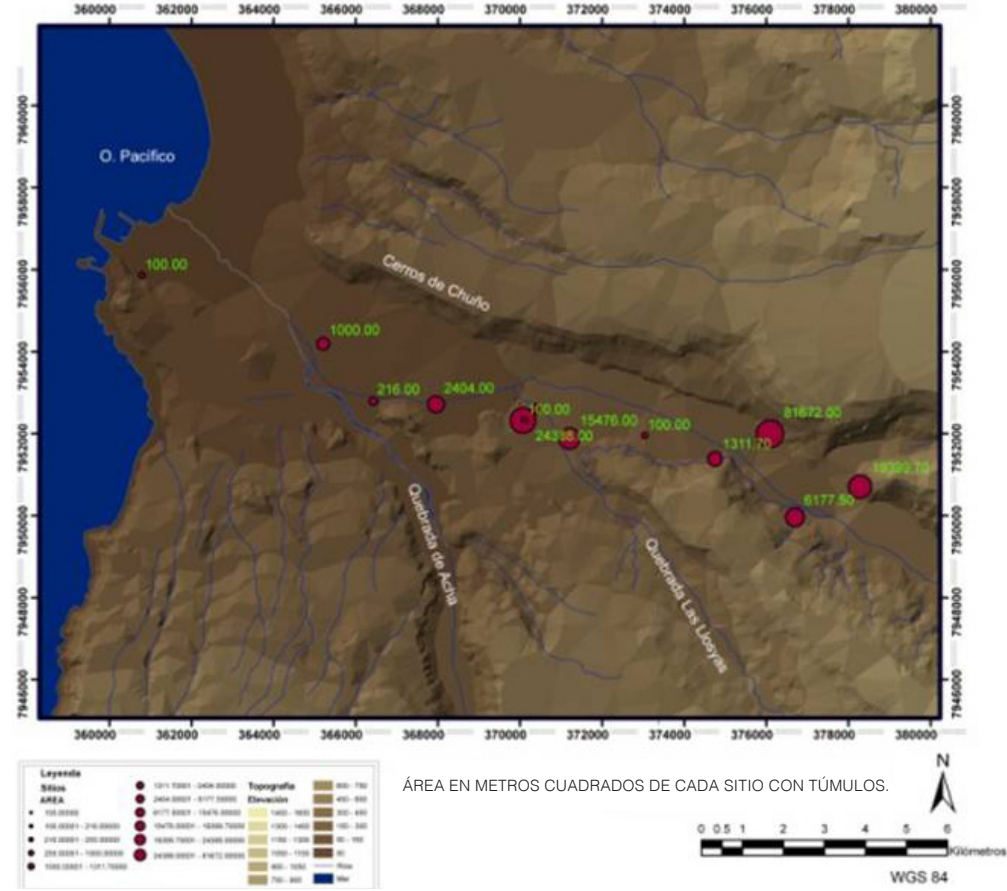

Fuente: Instituto Geográfico Militar, Zona A, escala 1:50.000. UTM WGS 84. 
mente, reutilizando materiales y levantando una construcción artificial en un mismo lugar recurrentemente. Foucault (1977) explica que la visibilidad es un elemento esencial en el entendimiento de cómo el poder está operando. La habilidad de controlar el acceso y la manipulación de los lugares es un rasgo fundamental que demuestra la naturaleza del poder como poder de dominación. Las celebraciones públicas en las sociedades son generalmente creadas conscientemente, con intenciones tácitas para validar la autoridad, unificar a un grupo, o promover alguna obra, porque son concebidas conscientemente; ellas encuentran su expresión espacial en un escenario especialmente regulado más que en un escenario espontáneo (Moore, 1996). Considerando lo anterior, es posible plantear un estudio de estos lugares a nivel arqueológico, incluyendo una perspectiva de cómo el poder y la legitimación de algunas sociedades se manifiesta en un escenario regulado tanto socialmente como materialmente.

Estos monumentos pueden servir como fronteras físicas para la comunicación de tipo visual o auditiva, como marcadores simbólicos, expresando diferencias entre los dominios, como barreras judiciales, definiendo la extensión de la posesión legal, y como límites administrativos para el manejo y control de los dominios (Lawrence, 1996). También pueden abrir la comunicación e integración de grupos humanos que manifiesten similares prácticas rituales, así como demarcar una identidad.

En la Figura $\mathrm{N}^{\circ} 7$ se destaca la visibilidad del valle desde el sitio Az-67, sector cerro Sombrero como de la pampa de Alto Ramírez; en ambos sectores se tiene una visión de los recursos de agua subterránea (vertientes) y de la costa (litoral) donde desemboca el río San José. En el caso de la visibilidad que ofrece el sitio Az-12 (Figura $N^{\circ}$ 9a), este se halla en un sector de cerros más elevados en relación con los túmulos de las Maitas (Az-142), lo que le da una visión total del curso medio del valle donde se hayan las vertientes El Gallito, la Media Luna y la Mita Chica.

Las Figuras $\mathrm{N}^{\circ}$ 9a) y $\mathrm{N}^{\circ}$ 9b) ilustran la visibilidad que presentan los túmulos del sector de pampa Alto Ramírez, Az-80, vértice norte y $\mathrm{Az}-17$. Este sector fue una extensa terraza donde se hallaron los mayores registros de asentamientos correspondientes al periodo agrícola aldeano temprano y medio. Estos túmulos están relacionados a los senderos que cruzan la pampa de Alto Ramírez y que formaron parte de antiguas rutas que bajaban de la sierra ariqueña, sector Livilcar, Chapiquiña y Belén, para desembocar en el sector costero de quebrada Quiani y la desembocadura del río San José. El sitio Az-21 (Figura No 9d) ilustra el dominio visual del sector suroeste del valle, el sector de cerro Sombrero, donde se ubicaba un antiguo humedal. Az-21, así como Az-22 y Az-24 se asocian a una antigua red vial cuyo destino final era la costa, a través de la quebrada de Quiani (lugar de antiguos asentamientos de pescadores) donde había una aguada, hoy seca, pero que fue utilizada etnográficamente por los pescadores de la costa sur de Arica.

La Figura $N^{\circ} 9 \mathrm{e}$ ) ilustra el complejo de túmulos de Az-70, el mayor de la ladera norte del valle de Azapa. Estos túmulos tienen una visibilidad, desde el valle medio hasta la costa de Arica, también hacia los recursos de agua subterráneas como la vertiente el Gallito, la Media Luna y El Socavón; se visualizan, además, los sectores de la ladera sur del valle desde Las Riberas hasta San Lorenzo. Por la ladera norte hay una estrecha comunicación visual con los sectores de cerro Moreno y las Ánimas, donde se registran los mayores túmulos de dicha ladera (Cuadro $N^{\circ} 1$ ).

\section{Discusión y consideraciones finales}

Los túmulos en general tienen forma de lomas, similar a los cerros. Los túmulos registrados por el sector sur van desde 1 a 30; sin embargo, se tiene que tener en cuenta que estos montículos corresponden a sitios arqueológicos arrasados por labores agrícolas, de tal manera que el número que se maneja en la actualidad es relativo en torno al número real que fueron construidos durante la fase Alto Ramírez en los distintos sectores del valle. Un solo ejemplo el año 1976 se contabilizan 350 túmulos para el valle de Azapa; en la actualidad se han prospectado 42 túmulos. 
Figura $\mathrm{N}^{\circ} 7$

Visibilidad entre asentamientos de túmulos

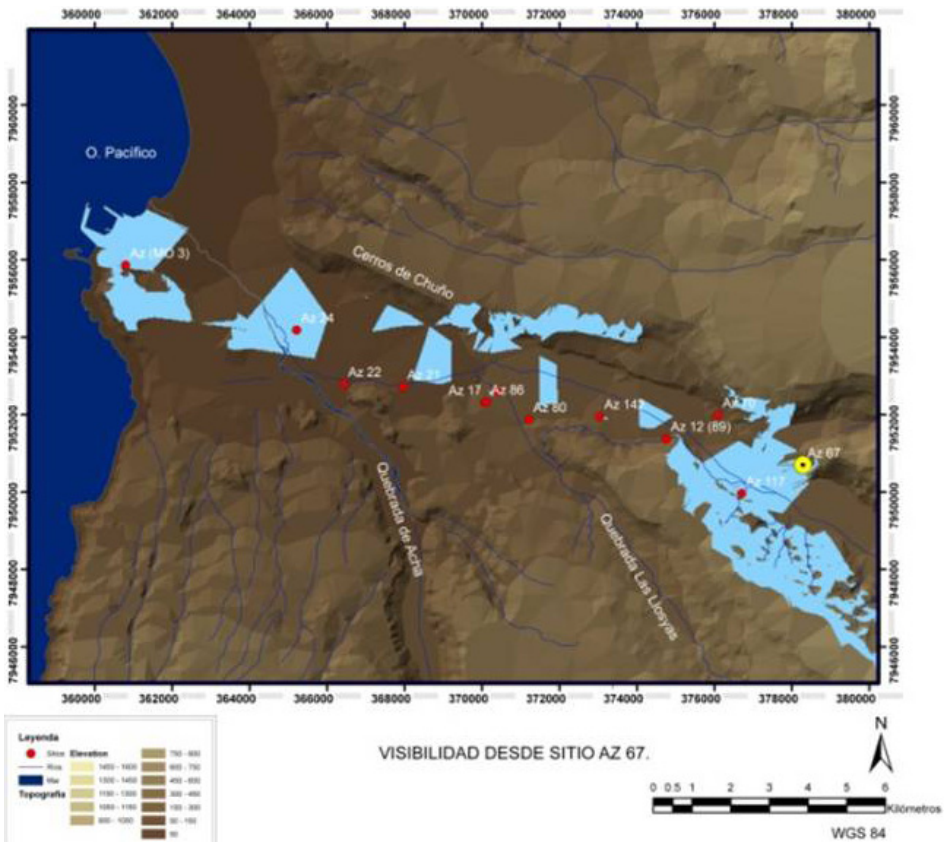

Fuente: Instituto Geográfico Militar, Zona A, escala 1:50.000. UTM WGS 84.

Figura $\mathrm{N}^{\circ} 8$

Visibilidad desde sitios Az 17 y 86

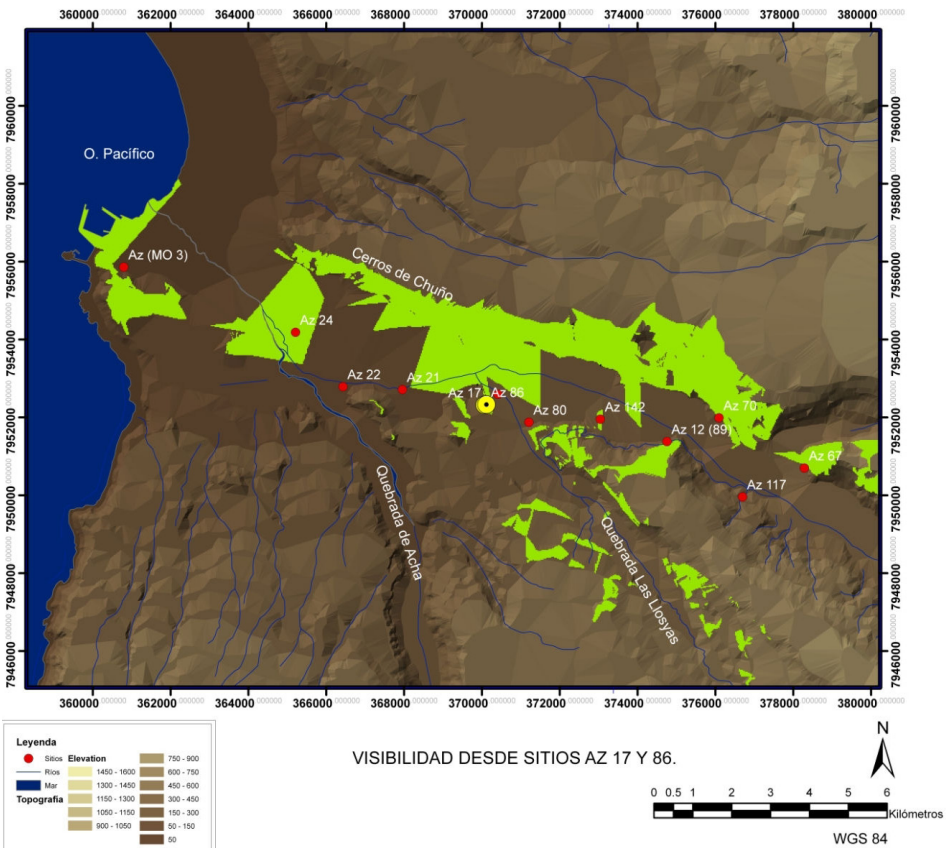

Fuente: Instituto Geográfico Militar, Zona A, escala 1:50.000. UTM WGS 84. 
Figura $N^{\circ} 9$

Patrones de visibilidad

a)

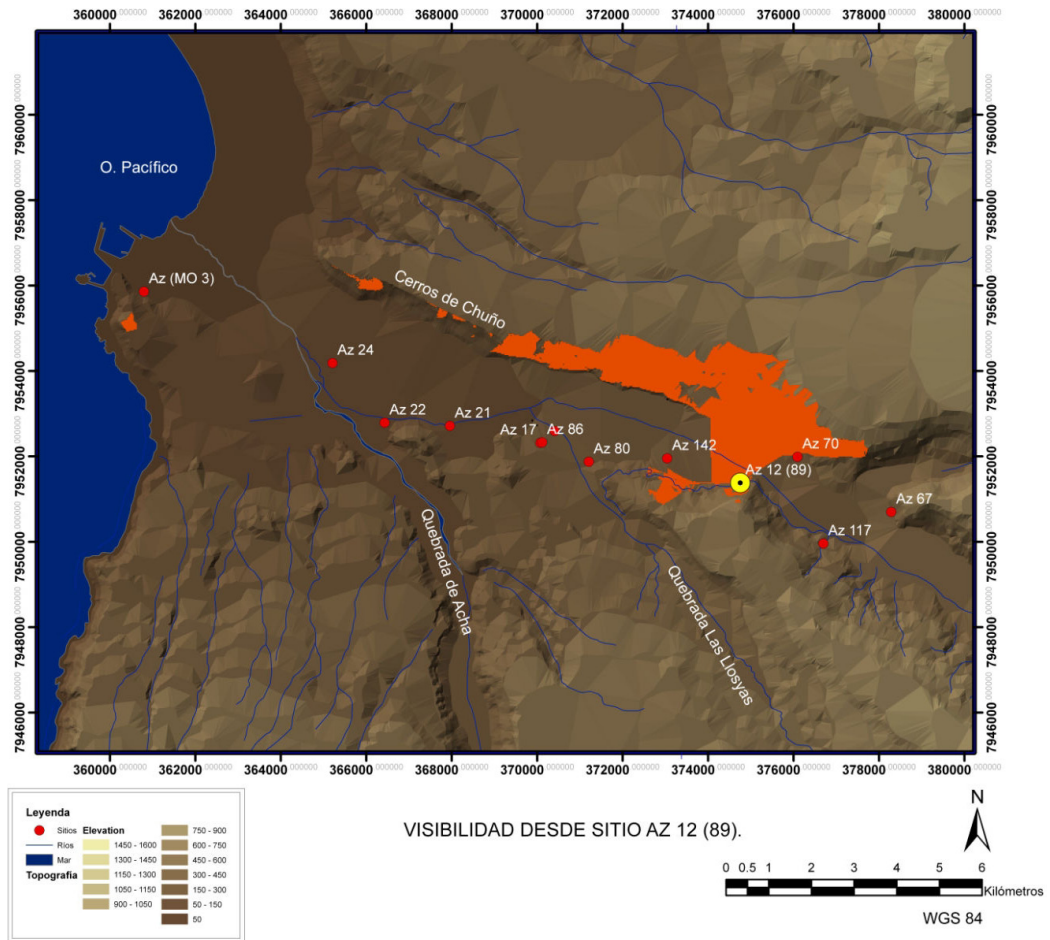

b)

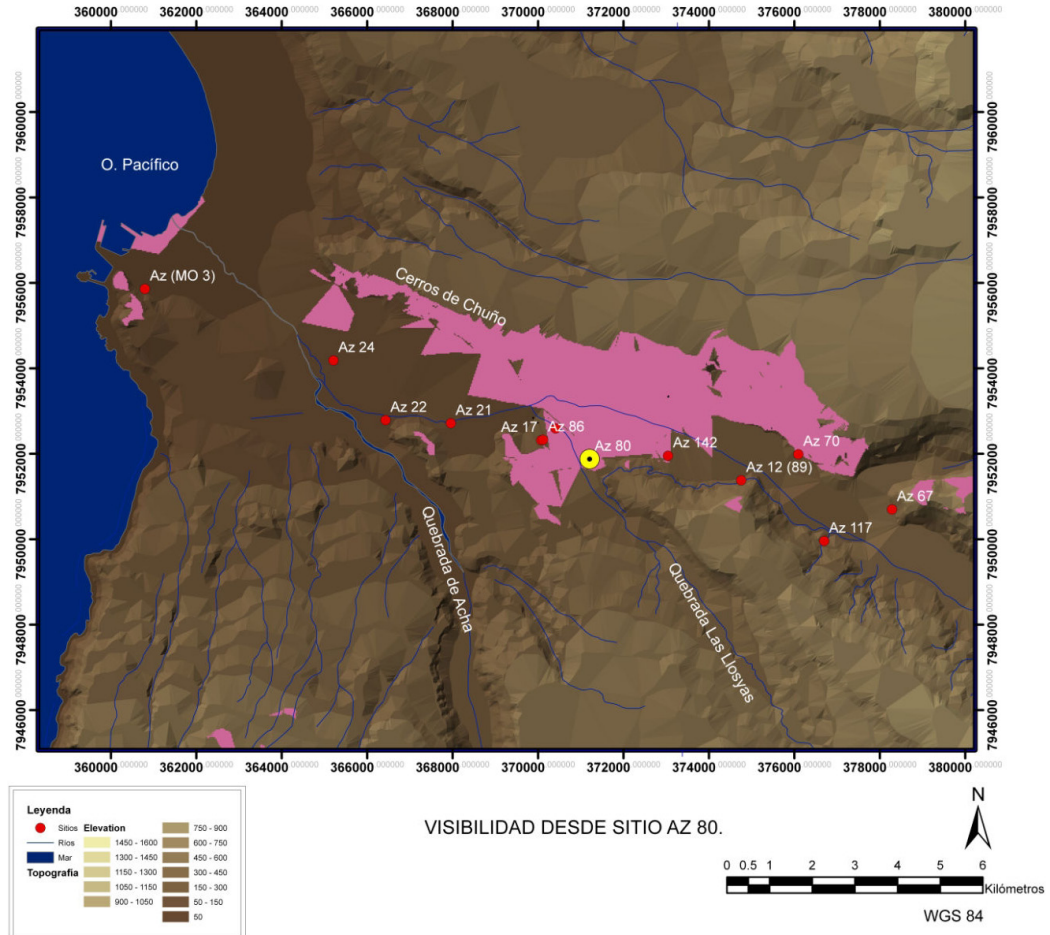


Figura $N^{\circ} 9$

(Continuación)

C)

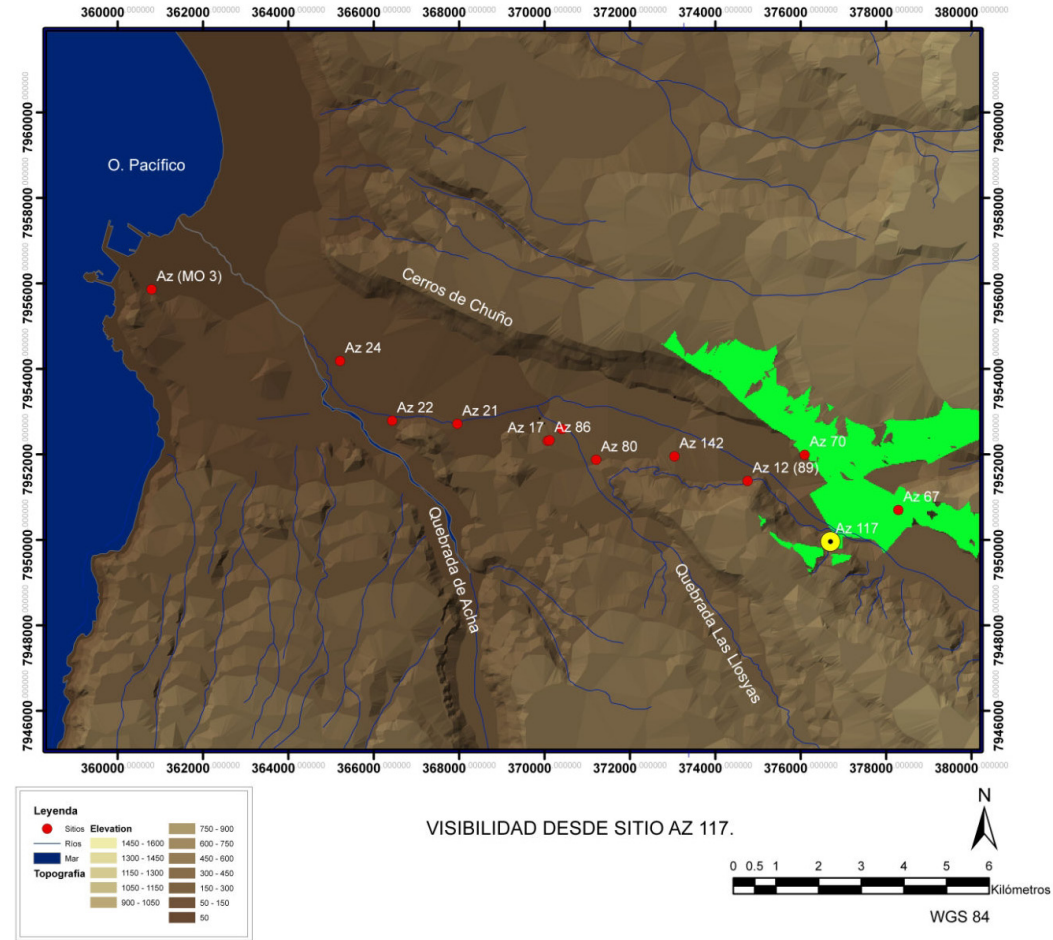

d)
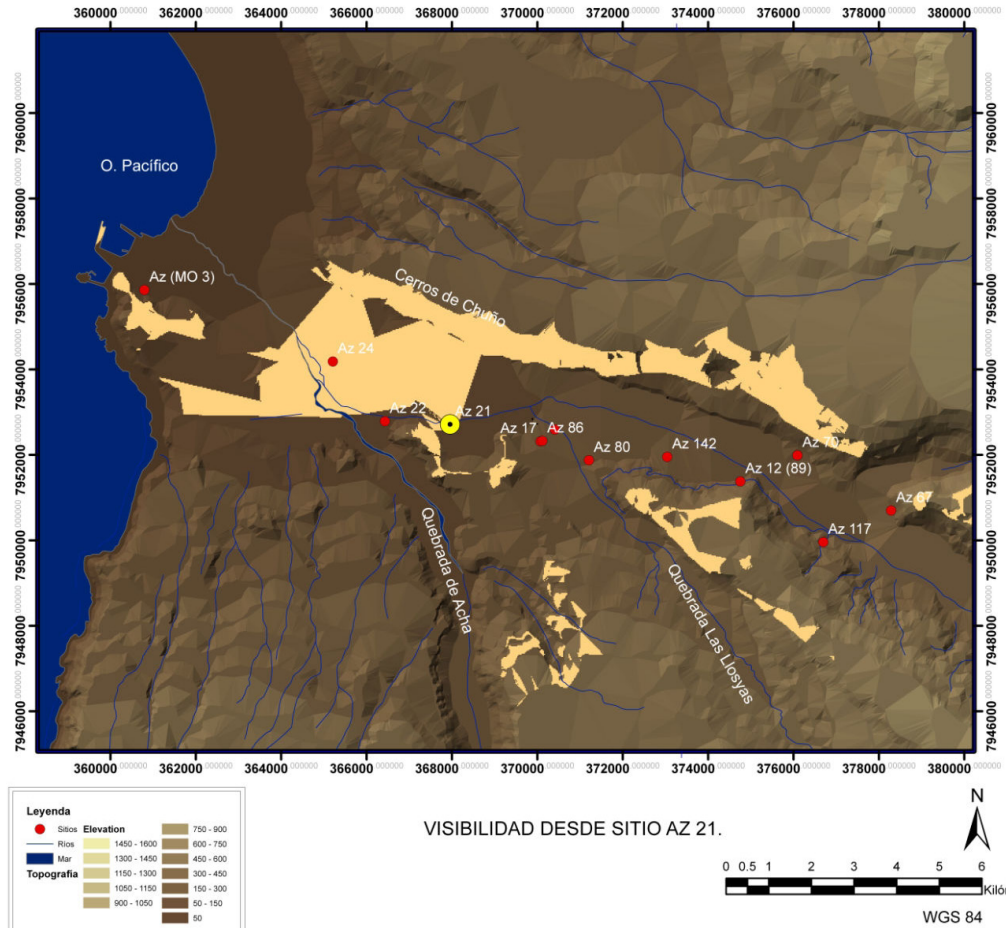

VISIBILIDAD DESDE SITIO AZ 21.

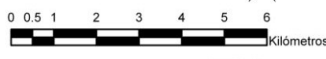

WGS 84 
Figura $N^{\circ} 9$

(Continuación)

e)

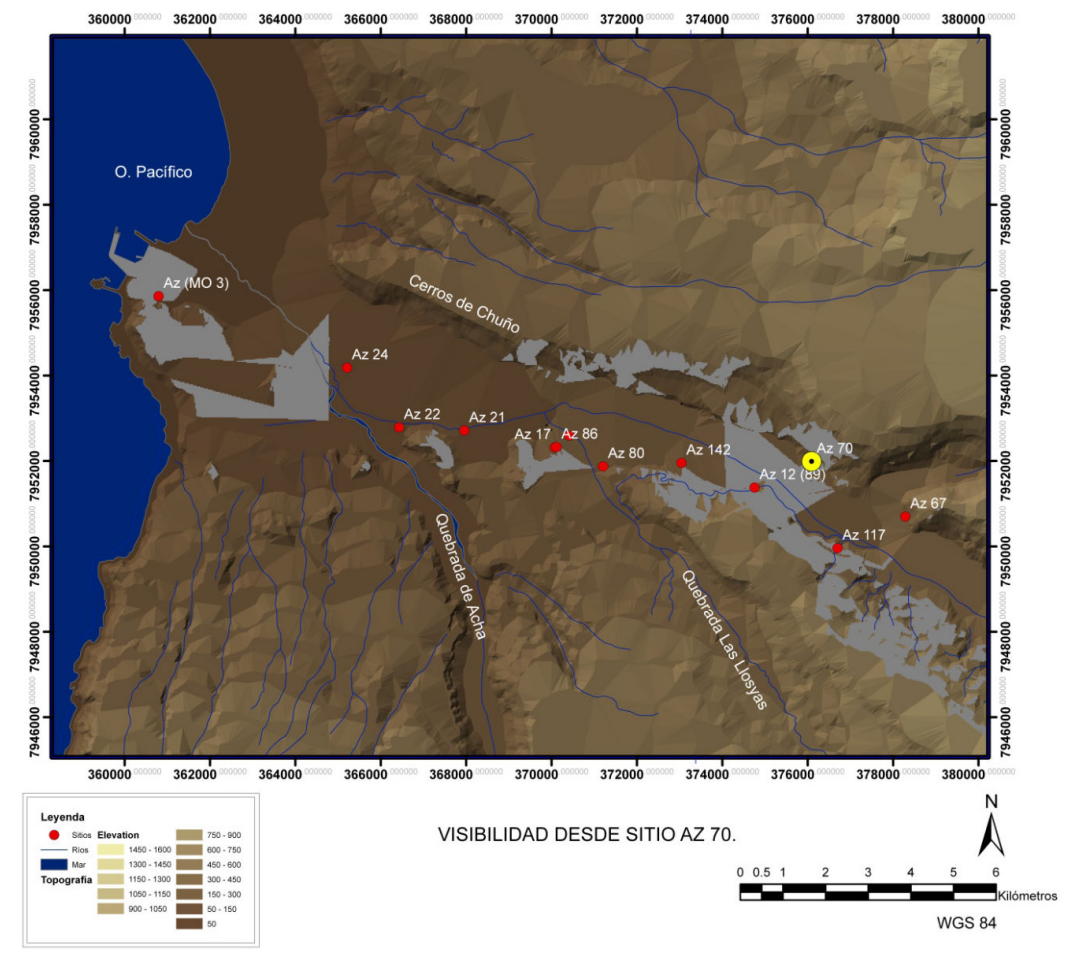

Fuente: Instituto Geográfico Militar, Zona A, escala 1:50.000. UTM WGS 84.

Estos túmulos se ubican en su gran mayoría en las terrazas fluviales y faldeos de cerros en la ladera sur del valle, ocupando lugares abiertos y estratégicos, cercanos a los afloramientos de agua (vertientes) donde recolectaron plantas, material utilizado en la construcción de las capas de fibra vegetal de los túmulos y recursos de subsistencia menor como camarones, raíces comestibles y roedores.

La relación diámetro distancia túmulos/ vertientes está dentro del rango de $1,3 \mathrm{~km}$, es decir, distancias relativamente cortas, lo que pudo haber permitido desplazamientos diarios de ir y venir más de una vez en el día.

En cuanto a los metros cuadrados que ocuparon los complejos de túmulos, el mayor de estos se ubica en la pampa Alto Ramírez, ocupando un área de $82.000 \mathrm{~m}^{2}$ y correspon- dería a un tercer rango donde se contabilizan 23 túmulos. El alto número de túmulos relacionado a una amplia visibilidad indicaría que en la pampa Alto Ramírez se habría concentrado un número mayor de población constructora de túmulos. Una mayor evidencia para plantear esta hipótesis se relaciona con la presencia y única aldea vinculada al periodo Formativo, AZ-83, la que fue construida a través de recintos de forma circular con hondonadas al piso.

Al parecer la pampa Alto Ramírez y la terraza San Miguel de Azapa serían las áreas nucleares de mayores asentamientos de las poblaciones formativas en el valle de Azapa. Por otro lado, en ambos sectores se hallan poblaciones previas vinculadas al periodo Formativo como AZ-14 en Alto Ramírez y AZ71 en San Miguel de Azapa, con fechas de 900 al 600 a. C. (Santoro, 1980). 
Cuadro $\mathrm{N}^{\circ} 1$

Ubicación, relación con vertientes y visibilidad de los túmulos del valle de Azapa

\begin{tabular}{|c|c|c|c|c|c|c|c|c|}
\hline \multirow{2}{*}{$\begin{array}{c}\text { Conjunto } \\
\text { de } \\
\text { túmulos }\end{array}$} & \multicolumn{2}{|c|}{ Coordenadas (UTM; 19K) } & \multirow{2}{*}{$\begin{array}{c}\text { Altura } \\
\text { (m.s.n.m.) }\end{array}$} & \multirow{2}{*}{$\begin{array}{l}\text { Sector del } \\
\text { valle de } \\
\text { Azapa }\end{array}$} & \multirow{2}{*}{$\begin{array}{l}\text { Relación } \\
\text { vertiente/ } \\
\text { humedal }\end{array}$} & \multirow{2}{*}{$\begin{array}{c}\text { Superficie } \\
\qquad\left(\mathrm{m}^{2}\right)\end{array}$} & \multirow{2}{*}{$\begin{array}{l}\text { Túmulos } \\
\left(\mathrm{N}^{\circ}\right)\end{array}$} & \multirow{2}{*}{$\begin{array}{l}\text { Visibilidad } \\
\text { túmulos }\end{array}$} \\
\hline & $\mathrm{N}$ & E & & & & & & \\
\hline Morro 3 & 7.955 .886 & 360.802 & 50 & $\begin{array}{l}\text { Faldeos del } \\
\text { Morro }\end{array}$ & $\begin{array}{l}\text { El Morro y } \\
\text { La Chimba }\end{array}$ & 100 & 1 & Az 67,70 \\
\hline $\begin{array}{l}\text { AZ - } 12 \\
(89)\end{array}$ & 7.951 .405 & 374.761 & 265 & San Lorenzo & $\begin{array}{l}\text { El Gallito } \\
\text { Mita Chica } \\
\text { Media Luna }\end{array}$ & $1.311,70$ & 3 & Az 70,142 \\
\hline AZ - 17 & 7.952 .344 & 370.079 & 178 & $\begin{array}{l}\text { Pampa Alto } \\
\text { Ramírez }\end{array}$ & $\begin{array}{c}\text { El Gallito } \\
\text { Mita Chica } \\
\text { Media Luna }\end{array}$ & 24.388 & 7 & $\begin{array}{c}\text { Az } 21,24,70 \\
67,12(89) \\
86,142\end{array}$ \\
\hline AZ - 21 & 7.952 .740 & 367.962 & 130 & La Tropilla & $\begin{array}{c}\text { Cerro San } \\
\text { Miguel, Pago } \\
\text { Gómez }\end{array}$ & 2.404 & 4 & Az 24 \\
\hline$A Z-22$ & 7.952 .814 & 366.435 & 102 & $\begin{array}{c}\text { Cerro } \\
\text { Sombrero }\end{array}$ & $\begin{array}{c}\text { Cerro San } \\
\text { Miguel, Pago } \\
\text { Gómez }\end{array}$ & 216 & 1 & Az 24 \\
\hline AZ - 24 & 7.954 .211 & 365.216 & 80 & $\begin{array}{c}\text { Cerro San } \\
\text { Miguel }\end{array}$ & $\begin{array}{c}\text { Cerro San } \\
\text { Miguel }\end{array}$ & 958,18 & 1 & Az 21 \\
\hline$A Z-67$ & 7.950 .725 & 378.291 & 318 & $\begin{array}{c}\text { Cabuza, } \\
\text { Cerro Moreno }\end{array}$ & $\begin{array}{l}\text { El Pejerrey, } \\
\text { Matavaca, } \\
\text { La Noria, } \\
\text { San Miguel, } \\
\text { El Socavón, } \\
\text { La Concepción } \\
\text { y Caniviri. }\end{array}$ & $19.399,70$ & 4 & \\
\hline$A Z-70$ & 7.952 .017 & 376.098 & 266 & $\begin{array}{l}\text { Cementerio } \\
\text { Cristiano }\end{array}$ & & 81.672 & 16 & \\
\hline AZ - 80 & 7.951 .902 & 371.213 & 203 & Las Llosyas & $\begin{array}{c}\text { El Gallito } \\
\text { Mita Chica } \\
\text { Media Luna }\end{array}$ & 15.476 & 23 & $\begin{array}{c}\text { Az } 17,70,86 \\
142\end{array}$ \\
\hline$A Z-86$ & 7.952 .355 & 370.123 & 185 & $\begin{array}{l}\text { Pampa Alto } \\
\text { Ramírez }\end{array}$ & $\begin{array}{c}\text { El Gallito } \\
\text { Mita Chica } \\
\text { Media Luna }\end{array}$ & 100 & 1 & $\begin{array}{c}\text { Az } 17,24,70 \\
67,12(89) \\
86,142\end{array}$ \\
\hline AZ - 117 & 7.949 .985 & 376.702 & 313 & Buen Retiro & $\begin{array}{l}\text { El Pejerrey, } \\
\text { Matavaca, } \\
\text { La Noria, } \\
\text { San Miguel, } \\
\text { El Socavón }\end{array}$ & $61.77,50$ & 4 & \\
\hline AZ - 122 & 7.952 .620 & 370.416 & 178 & $\begin{array}{l}\text { Pampa Alto } \\
\text { Ramírez }\end{array}$ & $\begin{array}{l}\text { El Gallito } \\
\text { Mita Chica } \\
\text { Media Luna }\end{array}$ & 255 & 1 & No se detectó \\
\hline AZ - 142 & 7.951 .980 & 373.048 & 205 & Las Maytas & $\begin{array}{l}\text { El Gallito } \\
\text { Mita Chica } \\
\text { Media Luna }\end{array}$ & 100 & 1 & \\
\hline AZ - 146 & 7.951 .913 & 373.338 & - & & & 66 & 1 & \\
\hline AZ - 147 & 7.953 .609 & 372.208 & - & Las Ánimas & $\begin{array}{l}\text { El Gallito } \\
\text { Mita Chica } \\
\text { Media Luna }\end{array}$ & 483,19 & & No se detectó \\
\hline
\end{tabular}

Fuente: Elaboración propia. 
Respecto a la visibilidad, los mayores rasgos se encontraron en los complejos AZ-67, Cerro Moreno, AZ-70, San Miguel de Azapa, AZ-80, AZ-17 y AZ-86, pampa Alto Ramírez, Az-142 y 146, Las Maitas; todos estos conjuntos de túmulos presentan una alta visibilidad que incluye desde la costa de Arica hasta el encajonamiento del valle a la altura del km 25. El dominio visual permitió a las poblaciones formativas posiblemente calcular el tiempo y distancia de un complejo funerario a otro, así como conocer los recursos vegetales y faunísticos que cada humedal y vertientes ofrecían (Figuras $\mathrm{N}^{0} 10$ y $\mathrm{N}^{\mathrm{0}} 11$ ).

Siguiendo a Criado (1993), del análisis de visibilidad de los túmulos se registra que estas construcciones visuales fueron resultado de la organización y planificación social que las poblaciones formativas hicieron del espacio ocupado. La determinación de construir monumentos de forma monticular pudo ser una estrategia de la sociedad Alto Ramírez tomando como modelo la figura del cerro, los que habrían constituido las deidades tutelares relacionadas con el mito de origen de estas poblaciones (Muñoz y Gutiérrez, 2011).
En el caso de las poblaciones Alto Ramírez, el performance del poder pudo haber operado a través del culto a los ancestros, situación que los habría llevado a construir los túmulos. Las celebraciones públicas como las que se dieron en los túmulos, fueron creadas conscientemente, con intenciones tácitas para validar la autoridad, unificar a un grupo, o promover alguna obra de los ancestros (Isbell, 1997). Se piensa que los rituales de la muerte, como en el caso de las poblaciones constructoras de túmulos, fueron realizados en escenarios especialmente regulados, más que en un escenario espontáneo (Moore, 1996). La construcción de los túmulos sumado al traslado de entierros, cuerpos que fueron traídos de otros lugares, sugieren que toda esta estructura funeraria se hizo bajo un escenario regulado tanto social como materialmente.

Finalmente, los túmulos pudieron haber tenido la función de abrir la comunicación e integración de grupos humanos en el valle de Azapa, las que pudieron tener similares prácticas rituales, lo cual los pudo llevar a definir y demarcar una identidad.

Figura $\mathrm{N}^{0} 10$

Estructura interna de los túmulos AZ-67, túmulo 1 y AZ-24, túmulo 1

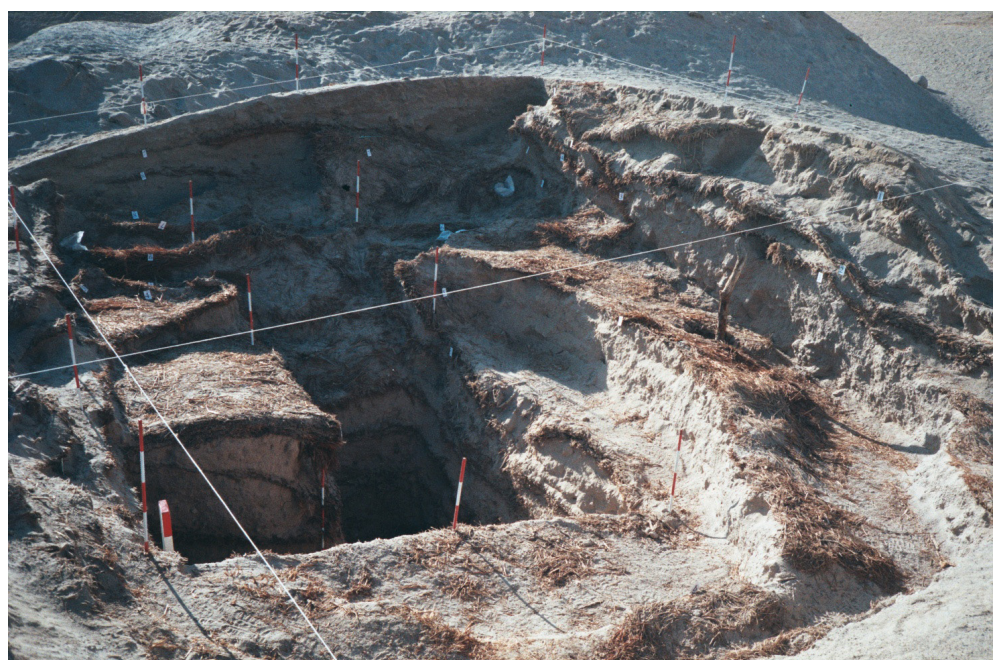

Fuente: Colección personal de los autores. 
La construcción de los túmulos al parecer obedeció a un patrón estructural de origen costero donde la idea de levantar montículos tal vez tuvo como modelo el medio donde las poblaciones se desenvolvieron; específicamente los cerros que conformaron las laderas del valle de Azapa; por otro lado, los elementos estructurales con que levantaron o construyeron los túmulos obedecieron a componentes ligados con los recursos que ofrecía el medio. El patrón de entierro y las ofrendas que caracterizan los contextos funerarios presentan un estilo que se remonta desde el periodo Formativo Temprano, fase Faldas del Morro y Azapa, rasgos que definen el momento en que los pescadores del litoral comenzaron a integrarse al proceso agrícola temprano.

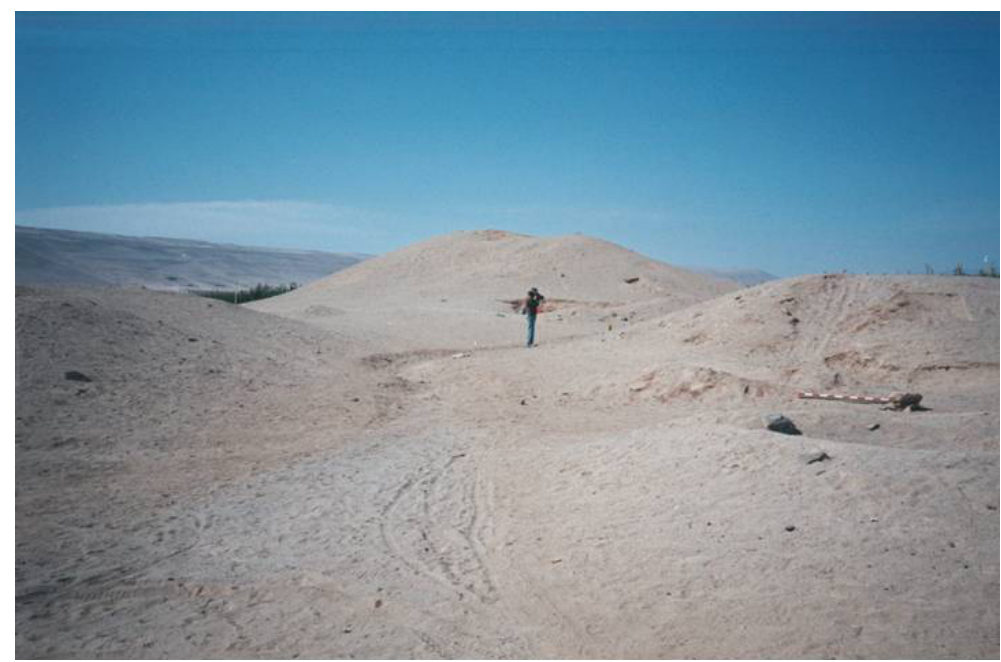

Fuente: Colección personal de los autores.

\section{Referencias bibliográficas}

AUGÉ, M. Los "No Lugares". Espacios del Anonimato. Barcelona: Gedisa, 2000.

BIRD, J. Excavation in northern Chile. Anthropological Papers of the American Museum of Natural History, vol. XXXVIII, 1943, p. 314.

BRADLEY, R. The significance of Monuments. On the Shaping of Human Experience in Neolithic and Bronze Age Europe. Londres: Routledge, 1998.

CLARKE, D. Spatial Archaeology. New York: Academic Press, 1997.
CRIADO, F. Límites y posibilidades de la arqueología del paisaje. Spal, 1993, No 2, p. 9-55.

DAUELSBERG, P. Contribución a la arqueología del valle de Azapa. Boletín Museo Regional de Arica, 1995, p. 36-55.

DILLEHAY, T. Mounds of Social death: araucanian funerary rites and political succession. In: DILLEHAY, T. (ed.). Tombs for the Living: Andean Mortuary Practices. Washington: Dumbarton Oaks research library and colletion, 1991, p. 281-313.

ESPOUEYS, O. Archivo: inventario de sitios arqueológicos en los valles de Arica. 
Arica: Oficina de Registro, Museo San Miguel de Azapa, Departamento de Antropología. Universidad de Tarapacá, Arica, 1973.

FOCACCI, G. Excavaciones en Playa Miller 7, Arica (Chile). Chungará, 1974, № 3, p. 23-74.

FOCACCI, G. y ERICES, S. Excavaciones en los túmulos de San Miguel de Azapa (Arica- Chile). Actas del VI Congreso Nacional de Arqueología Chilena, 1972/1973, p. 68-74.

FOUCAult, M. El Ojo del Poder. En Panóptico de Jeremías Bentham. Madrid: Ediciones de la Piqueta, 1971.

GIANOTTI, C. Arqueología del paisaje en Uruguay. Origen y desarrollo de la arquitectura en tierra y su relación con la construcción del espacio doméstico en la prehistoria de tierras bajas. En: MAMELI, E. y MUNTAÑOLA, E. América Latina: realidades diversas. Barcelona: Instituto Calalán de Cooperación Iberoamericanba-Casa de América, Colección AMER\&Cat 13, 2005 , p. 1-25.

ISBELL, W. H. Mummies and Mortuary Monuments. A postprocessual Prehistory of Central Andean Social organization. Austin: University of Texas Press, 1997.

KNAPP, B. \& ASHMORE, W. Archaeological landscape: constructed, conceptualized and ideational. In: ASHMORE, W. \& KNAPP, B. (eds.). Archaeologies of Lanscape. Contemporary Perspectives. Oxford: Blackwell, 1999, p. 1-30.

LAWRENCE, R. The multidimensional nature of boundaries: an integrative historical perspective. In: PELLOW, D. (ed.). Setting Boundaries. The Anthropology of Spatial and social Organization. London: Bergin y Harvey, 1996, p. 9-36.

LÓPEZ MAZZ, J. M. Las estructuras tumulares (cerritos) del Litoral Atlántico uruguayo. Latin American Antiquity, 2001, vol. 12, No 3, p. 1-25.

MOORE, J. The Archaeology of Plazas and the Proxemics of Ritual. American
Anthropologist, 1996, vol. 98, $\mathrm{N}^{\circ} 4$, p. 789-802.

MUÑOZ, I. Túmulos funerarios: evidencias del proceso de agriculturación en los valles bajos de Arica. Memoria para título de arqueólogo. En: Antofagasta, Departamento de Arqueología, Universidad del Norte, 1980.

MUÑOZ, I. Enterramientos en túmulos en el valle de Azapa: nuevas evidencias para definir la fase Alto Ramírez en el extremo norte de Chile. Chungará, 1987, № 19, p. 93-128.

MUÑOZ, I. El Período Formativo en el Norte Grande (100 a. C. a 500 d. C.) En: HIDALGO, J.; SCHIAPPACASSE, V.; NIEMEYER, H.; ALDUNATE, C. y SOLIMANO, I. (eds.). Culturas de Chile. Prehistoria. Desde sus Orígenes hasta los Albores de la Conquista. Santiago: Editorial Andrés Bello, 1989, p. 107-128.

MUÑOZ, I. Spatial dimensions of complementary resource utilization at Acha 2 and San Lorenzo. In: ALDENDERFER, $M$. (ed.). Domestic architecture, ethnicity and complementary in the south Central Andes. lowa: lowa Press, 1993, p. 94-102.

MUÑOZ, I. Poblamiento humano y relaciones Interculturales en el valle de Azapa: nuevos hallazgos en torno al periodo Formativo y Tiwanaku. Diálogo Andino, $1995 / 1996, N^{\circ} 14 / 15$, p. 241-278.

MUÑOZ, I. Agua y monumentalidad en el valle de Azapa: indicadores del uso del espacio en las poblaciones Alto Ramírez, Periodo Formativo, Norte de Chile. Chungará, 2009, en prensa.

MUÑOZ, I. y GUTIÉRREZ, M. Túmulos funerarios. Arquitectura y monumento del paisaje desértico en las tempranas poblaciones agrícolas del valle de Azapa, norte de Chile. Anales de la XXIV Reunión Anual de Etnología, 2011, tomo I, p. 63-78.

NúÑEZ, L. Hacia la producción de alimentos y la vida sedentaria (5.000 a.C. a 900 d.C.). En: HIDALGO, J.; SCHIAPPACASSE, V.; NIEMEYER, H.; 
ALDUNATE, C. y SOLIMANO, I. (eds.). Prehistoria de Chile. Desde sus orígenes hasta los albores de la Conquista. Santiago: Editorial Andrés Bello, 1989, p. 81-106.

RIVERA, M. Nuevos aportes sobre el desarrollo cultural altiplánico en los valles bajos del extremo norte de Chile, durante el período Intermedio Temprano. En: UNIVERSIDAD DEL NORTE. Homenaje al $R$. P. Gustavo Le Paige. Santiago: Universidad del Norte, 1976, p. 71-81.

RIVERA, M.; SOTO, P.; ULLOA, L. y KUSHNER, D. Aspecto sobre el desarrollo tecnológico en el proceso de agriculturación en el norte prehispánico, especialmente Arica (Chile). Chungará, 1974, № 3, p. 79-107.

ROMERO, A.; SANTORO, C.; VALENZUELA, D.; CHACAMA, J.; ROSELLO, E. y PIACENZA, L. Túmulos, ideología y paisaje de la fase Alto Ramírez del valle de Azapa. Chungará, 2004, vol. especial, tomo I, p. 261-272.

SANTORO, C. Fase Azapa, transición del Arcaico al desarrollo agrario inicial en los valles bajos de Arica. Chungará, 1980, vol. 6, p. $46-56$. 